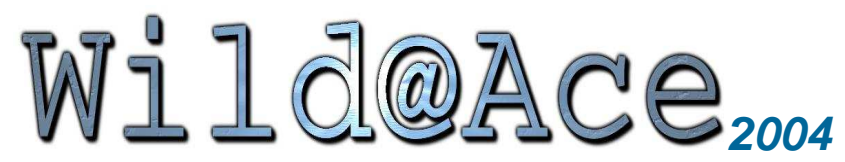

\section{Industry and Labour Dynamics II}

Proceedings of the wild@ace 2004 conference

10

LABORsim: An Agent-Based Microsimulation of Labour Supply. An application to Italy

Roberto Leombruni and Matteo Richiardi 


\title{
LABORsim: An Agent-Based Microsimulation of Labour Supply. An application to Italy
}

\author{
- november 2005 -
}

\author{
Roberto Leombruni, LABORatorio R. Revelli-Centre for employment studies \\ Matteo Richiardi, LABORatorio R. Revelli-Centre for employment studies
}

\begin{abstract}
Most Oecd Countries are experiencing rapid population ageing. Italy adds to this picture a very low labour market participation of the elderly, so that most projections of the impact of ageing on the labour market are rather pessimistic. However, there are other long run modifications currently underway that will presumably have a sizeable impact on the labour market, above all changes in retirement legislation, in educational choices and participation behaviour. In this paper we present $L A B O R$ sim, an agent based microsimulation model of labour supply, which offers new insights on the likely evolution of the labour force in the next decades in Italy. LABORsim integrates current demographic projections with simulation modules modelling retirement rules, retirement behaviours, migration, education and participation choices, plus a consolle to implement various policy scenario analyses. When all these factors are taken into account, projections for coming decades are not that pessimistic. In most scenarios, the overall participation rate is expected to increase steadily for the next two decades, while shortages in the labour force supply and an unfavourable dynamic for the economic dependency rate are expected to show up only after 2020, when the baby boom generations will arrive at retirement age. This is not enough, however, to allow Italy to meet the EU Stockolm and Lisbon targets for male and female employment rates for many decades to come. The sharp increase in participation rates for the elderly (aged 55-64), mainly driven by the recent changes in the retirement eligibility criteria, will make it possible to meet the Stockholm target of an employment rate of 50\% in this age group by 2015 , i.e. with only 5 years of delay.
\end{abstract}

JEL Classification: E24, H3, H55, I2, J1, J2, J6, N4, O52, C63

Keywords: microsimulation, participation, employment, retirement, education, policy evaluation 


\section{Introduction}

In the next decades most Oecd Countries will experience rapid population ageing, because of the increase in life expectancy that took place in the second half of the last century, and to a simultaneous sharp decrease in fertility rates. This will have strong consequences both on the sustainability of social security systems - financed in most cases through a pay-as-you-go mechanism - and on the labour market, with possible labour supply shortages. Within this general picture Italy is no exception, having one of the oldest populations among Oecd countries. What is worse, Italy also has one of the lowest participation rates in the labour market, particularly for women and older workers. Ageing and low participation, taken together, justify the very pessimistic projections that are currently made about the evolution of economic dependency ratios in the coming decades.

Most projections, however, are based on a very simplistic extrapolation of cross-sectional participation rates as measured today. Oecd [2004], for instance, applies the participation rates measured in 2000 to demographic projections, and estimates a dramatic reduction in the consistency of the labour force - dropping from 24 to 17 million by 2050 - and an increase in the economic dependency ratio that is the second worst among all the Oecd country forecasts.

These kind of projections are unsatisfactory in many respects. First, participation choices should be viewed in a life cycle perspective. To extrapolate cross-sectional data observed today can produce paradoxical results for the pseudo-individuals belonging to the new cohorts simulated: they would participate little when they are young - since young people today generally go to school and they would participate little when they get old - since today's older workers generally started working very early, and exit early the labor market.

Second, existing low employment rates for people aged 50 and over, in Italy, are probably below their long run equilibrium. With respect to women, many of those who are not participating in the labour market actually never worked during their lives - again, in a life cycle perspective, they once and for all decided to "offer" their labour services within the family. In the data, however, a trend towards a higher participation is clearly detectable for new cohorts. Moreover, both men and women during the last two decades took advantage of the very generous early-retirement schemes available up to the Eighties. Such a "filtering out" of the labour force has had a negative impact on the participation rates observable today for older workers, but will vanish in the future due to the major reforms of the pension system completed in the last twelve years.

In this paper we present an agent based microsimulation model of labour supply, which offers new insights on the likely evolution of the labour force in the coming decades in Italy. The main focuses of the model are on demography, migration, retirement rules, retirement behaviours, education and participation choices. All behavioural rules implemented are cohort specific, and have been estimated based on Italian Central Statistical Office (Istat) and Eurostat data over the years 1993-2003. The eligibility criteria implemented for the pension system carefully mimics the actual three-layer retirement rules in force in Italy. When all these factors are taken into account, projections for future decades are not that pessimistic. Even in the less favourable scenario assuming that the positive trend in higher participation in education and in higher labour force participation for women will cease - the overall participation rate is expected to increase steadily for the next two decades.

The paper is structured as follows. Section 2 deals with some background issues on participation. Section 3 presents the model. Section 4 discusses the simulation results in the standard scenario. Section 5 concludes. 


\section{Some background issues on participation in Italy}

The process of population ageing currently underway in Italy is more pronounced than in most other Oecd countries. In the last decades the total fertility rate has declined steeply, going below the replacement rate of 2.1 at the beginning of the $80 \mathrm{~s}$ and reaching 1.24 in $2000^{1}$. At the same time, life expectancy is among the highest among Oecd countries. Even though a slight recovery in fertility rates is expected in the future, the transition process to the new demographic regime will have a deep impact on the age structure. In the next two decades, the baby boom generations of the 60s and early 70s will become eligible for retirement, and will be replaced by new labour force cohorts roughly half in size ${ }^{2}$. By 2050, more than one in three Italians will be over the age of 65 .

An additional source of concern about Italy is the fact that the participation rates of older people are peculiarly low. Figure 1 compares participation rates for people aged 55-64 in a selection of EU countries. Italy is $14^{\text {th }}$ out of 16 , and contrary to most countries has experienced a decrease in the participation rates during the Nineties.

Figure 1. Participation rates in 1990 and 2002, people aged 55-64, various EU countries.

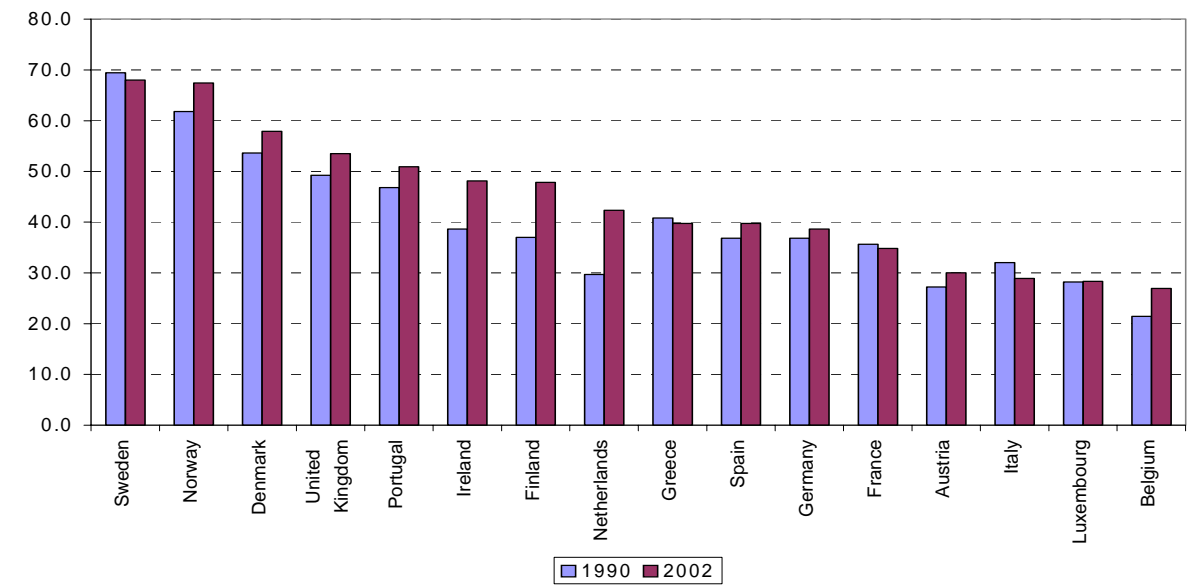

Source: Eurostat LFS 2002.

Putting together ageing and low participation of older workers it is straightforward to build future scenarios in which the economic dependency rate - the ratio of people out of the labour force over those who participate - will become hardly sustainable. Oecd launched in 2001 a thematic review on this issue, and built projections about the future evolution of old age dependency rates in Oecd member countries (see for instance Oecd [2004]). They applied the participation rates measured in 2000 by gender and five-year age groups to the best available demographic projections, and compared the evolution of a demographic and an economic old age dependency rate (see Figure 2).

\footnotetext{
${ }^{1}$ Here and in what follows we refer to the "central" scenario of the population projections produced by the Italian Statistical Office (Istat), see http://demo.istat.it/index.html.

${ }^{2}$ New births averaged 950,000 during 1960-69, and 890,000 during 1970-1974. In recent years (1998-2002) they averaged 530,000 per year (see Marano and Sestito [2005]).
} 
Figure 2. Old age demographic and economic dependency rates, Oecd countries.
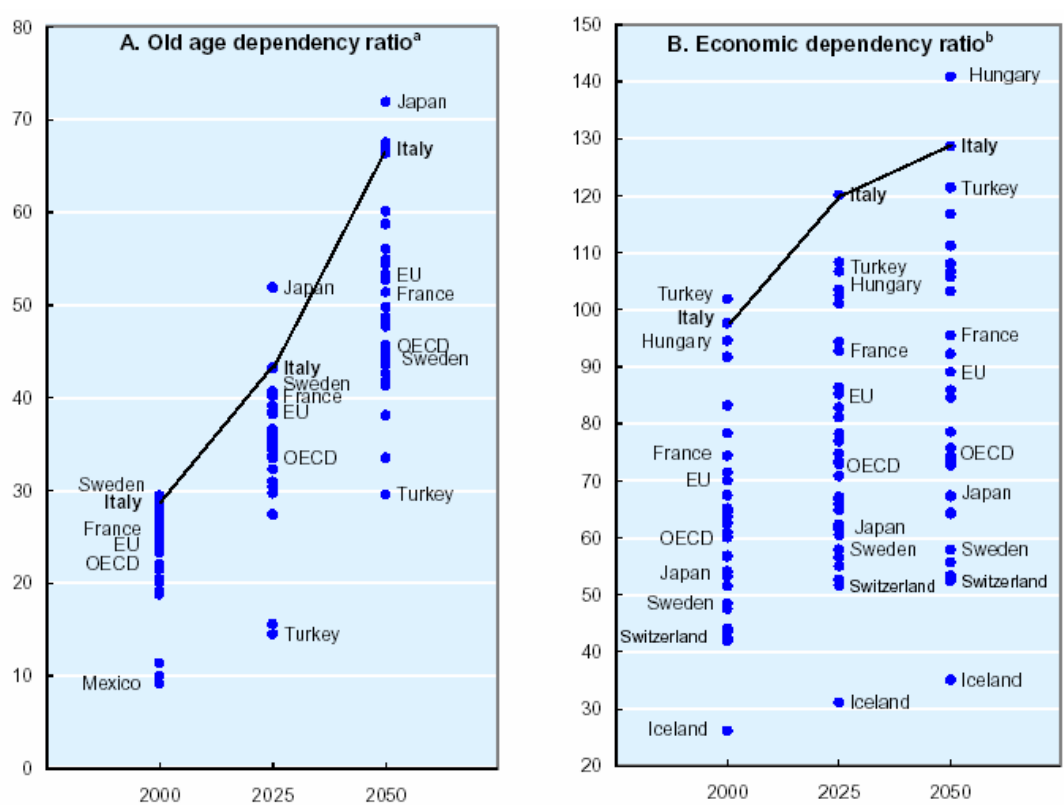

Panel A, left: People aged 65 and over to people in the age bracket 20-64.

Panel B, right: People out of the labour force to those in the labour force, excluding those under 20.

Source: Oecd [2004].

The most revealing comparison is about Italy and Japan. Both countries are facing the most rapid ageing in the population (left panel). In Japan, however, workers stay longer in the labour market, so that the share of those who are not active remains below the Oecd average (right panel). On top of ageing, Italy adds one of the lowest participation rates for people aged 50 and over, so that the economic dependency rate is expected to reach a record level of almost $130 \%$ by 2050 .

These "gloomy" estimates do not stand alone. Figure 3 shows projections by the Italian Welfare Ministry for the European Commission: the economic dependency rate is expected to follow closely the trend of the demographic dependency rate.

Figure 3. Old age demographic and economic dependency rates, Italy.

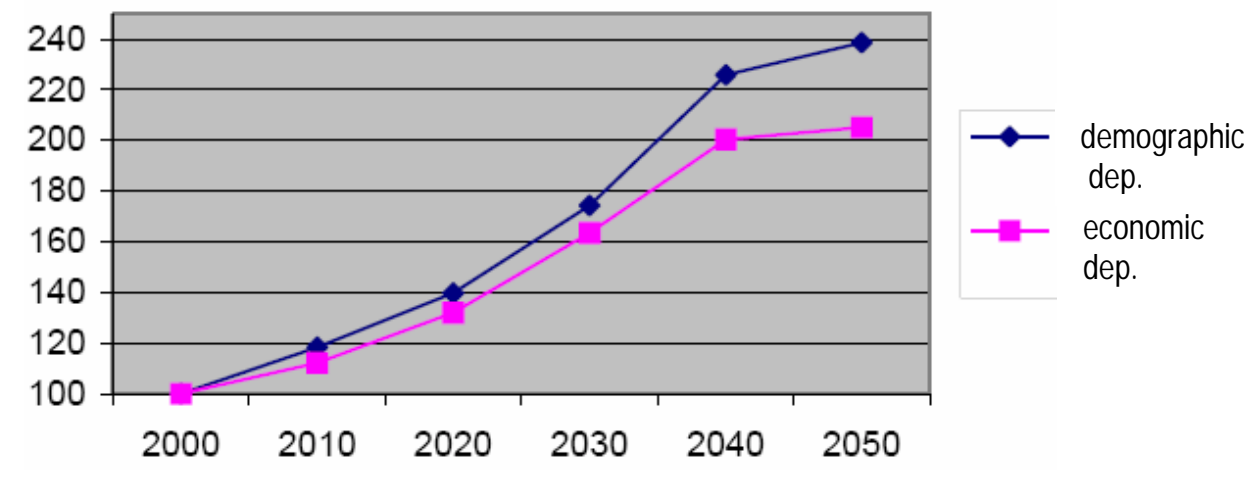

Source: EC [2003]. Year $2000=100$

How reliable are these projections? While the future evolution of the population age structure reflects a secular change that can hardly be questioned, the use of cross-sectional participation rates by age and gender is unsatisfactory under many respects. The general argument is that participation choices should be viewed in a life cycle perspective, since the choices made by young people regarding education and entry into the labour market have an impact on their subsequent working career. The use of cross-sectional evidence mixes behaviours of young individuals with the 
behaviour of their contemporary elders, that as a rule are not coherent to each other. For what concerns the Italian case, this general argument goes together with the following points.

First, the legislation has changed. The current low participation rate of older people in Italy (both males and females) is linked with retirement legislation that is no longer in force. The old system was particularly biased towards early withdrawal from the labour market, both because it allowed seniority pensions, and because of the defined benefit rule used for the computation of pension entitlements, that generally provided a financial incentive to retire as soon as one became eligible. The retirement legislation in force today has higher age requirements, and - because of the introduction of a defined contribution rule - does not embed incentives for an as-soon-as-possible retirement behaviour.

Second, the working careers of individuals have shifted forward in the life cycle. Actual low participation of the older people in Italy reflect working careers that on average started well before what can be observed for new cohorts today. In Figure 4 we considered two cohorts: those that in 2001 where aged 60-65, and those that will be in the same age bracket in thirty years. Plotting the declared age at which they began their working life, from the European Community Household Panel (Echp), the shift towards later entry in the labour market is clear. This means that individuals of actual cohorts will arrive at retirement age with shorter seniority in comparison with those who retired during the last decades $^{3}$, and this will postpone their retirement because seniority requirements (aside from age requirements) in the eligibility criteria will be met later.

Figure 4. Reported age at first job/business, two cohorts, 2001.

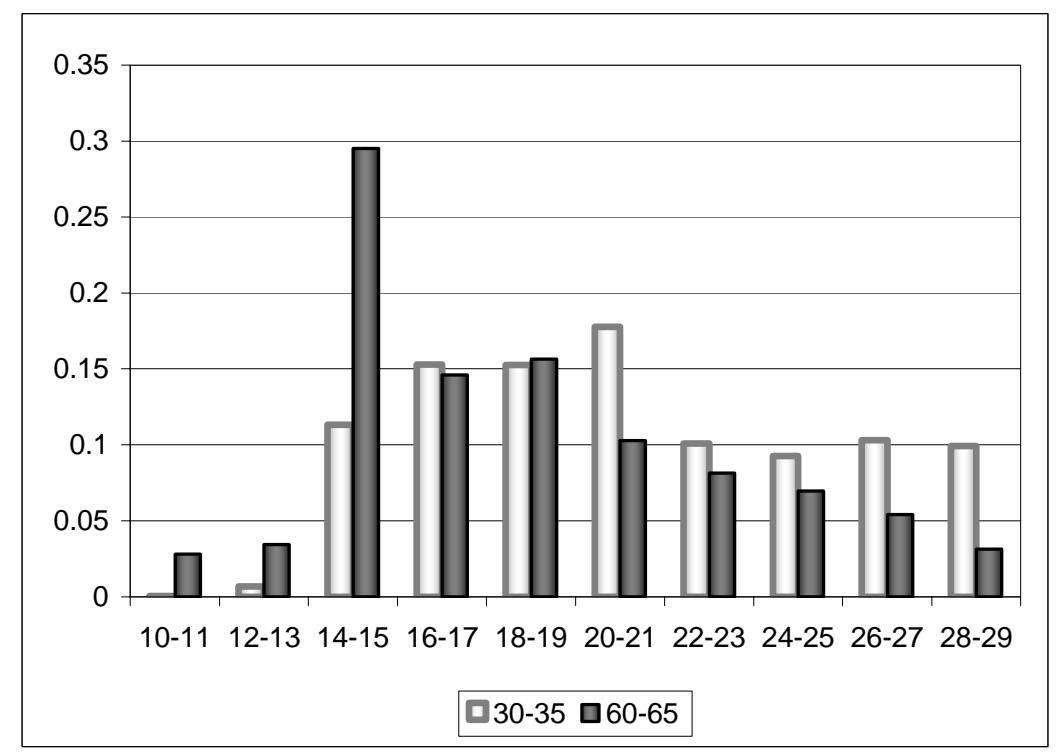

Source: Our calculations based on Eurostat data, ECHP, wave 6.

Note: Ages are grouped in 2-year classes in order to avoid heaping at even ages.

Strictly connected with the last point is the fact that newer generations have on average, in Italy, a higher level of education (see section on education below). Actually, later entries into the labour market can be explained by and large by higher educational participation. This will presumably have an additional, direct impact on the participation in the labour market of future older people, both because higher education has a positive effect on the employability of workers that is, on their capability of finding and retaining a job - and on their willingness to do it, since higher skilled jobs usually bear a lower disutility of work.

\footnotetext{
${ }^{3}$ The trend is the same for young people today, who experience on average more and longer unemployment spells with respects to what happened to older cohorts.
} 
Starting to work later may also affect retirement choices via wages, and consequently pensions. On the one side, shorter contribution spells mean lower pensions, given the same wage profile. Individuals will then have the incentive or the need to withdraw later from the labor market, in order to achieve the same standard of living when retired. On the other side, better educated people should have higher wage profiles. In this case they might then be willing to retire earlier. However, (i) as the supply of the skilled labor force increases, the returns to education may go down, and (ii) higher educated people may revise their standard of living upwards. Moreover, the Italian pension system pays little attention to the amount of contributions, in determining eligibility. ${ }^{4}$ Age and seniority are much more important. It is thus quite implausible that this consideration could reverse the causal link between higher education and later exit from the labour market.

Finally, the actual low participation of older women is linked with life cycle choices made many decades ago, when a large share of Italian women decided once and for all to "offer" their labour services within the family instead of within the labour market. A simple analysis of unconditional participation profiles of women by cohort reveal a trend towards a lower share of those who work within the family (see Figure 5). This is coherent with decreasing average household sizes that go together with decreasing fertility rates, and with a long run reduction in the gender differences related to attitudes towards the labour market.

Figure 5. Participation profiles by cohort, males (left panel) and females (right panel)
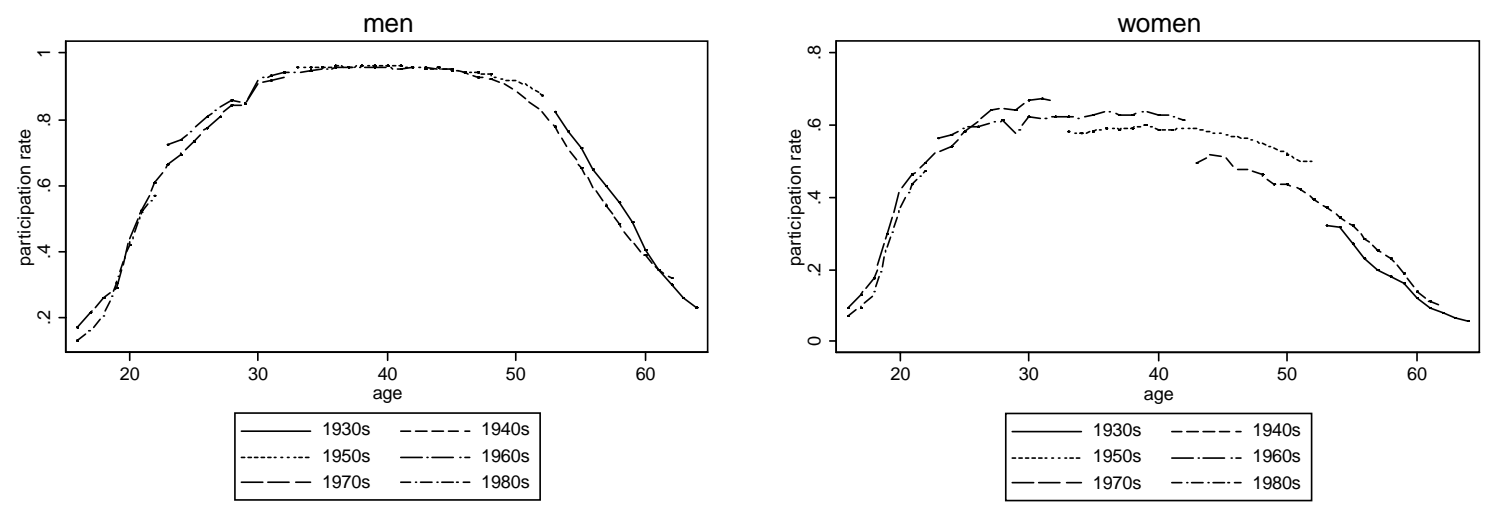

Source: Our calculations based on Istat data, RTFL, 1993-2003.

To sum up, while demographic trends indicate future scenarios where the older people will be a very large share of the population, this will not necessarily turn into high economic dependency upon people in the labour force. There have been many changes in the last decades - in retirement legislation, educational choices, working careers, the participation behaviours of women - that will have a long run impact on future participation in the labour force, and will probably countervail the demographic ageing of the population.

These issues point to the importance of a micro-foundation of the projections of participation rates, in order to dynamically take into account for all the socio-demographic and economic trends at work, and correctly simulate the effects of changes in legislation. Applying cross-sectional evidence to demographic projections, or even assuming convergence of gender and age-group cross-sectional participation rates to some Oecd averages, as also done by Oecd [2004], seems like no more than providing scenario analysis, and says very little about the likelihood of each scenario.

\footnotetext{
${ }^{4}$ A minimum level is required, in order to guarantee a minimum pension (equal to 1.2 times the amount of the benefits for poor people).
} 


\section{A micro-foundation of participation rates}

A natural way to overcome the problems outlined above is to use a dynamic microsimulation. Microsimulation modelling has been an active field of research since the seminal work of Orcutt in the 1950s [Orcutt, 1957]. Although for many years it has been confined to a small niche of practitioners, it is now being revitalized by a new wave of interest, partly due to the rise in computer power that has made it widely accessible. ${ }^{5}$ Microsimulation modelling involves the generation of data on individual units, rather than the analysis of pre-determined, "representative" groups or cells, or of the aggregate system as a whole (i.e. general equilibrium models), and are particularly suited for policy evaluation and scenario analysis. When microsimulations do not consider behavioural changes to a change in the environment (e.g. policy), they are defined as 'static' (e.g. tax-benefit models). Dynamic microsimulations on the other hand incorporate behavioural responses. ${ }^{6}$

In general, microsimulations consider many dimensions of socio-economic systems. However, we are interested here mainly in (i) education, (ii) participation, (iii) retirement, aside from the effects of demographic change. Among the dynamic microsimulation models surveyed in Zaidi and Rake, (2002) DYNASIM2 (USA, [Wertheimer, 1986]), CORSIM (USA, [Favreault and Caldwell, 1999]), MOSART (Norway, [Fredriksen, 1998]), DESTINIE (France, [Bonnet and Mahieu, 2000]) and SAGE (UK, [SAGE 2001-2004]) explicitly consider all the three issues above; DYNAMOD-2 (Australia, [King et al., 1999]) considers (i) and (ii) alone; PENSIM (UK, [Curry, 1996]) only (ii) and (iii).

A few microsimulation models are also available for Italy. Among those who have a similar approach to ours, the Bank of Italy's DYNAMITE model [Ando et al., 2004] focuses on household formation and income dynamics, while MIND [Vagliasindi et al., 2004] and DYNASIM ${ }^{7}$ [Mazzaferro and Marciano, 2005] focus on the distributional impact of the demographic evolution and social security provisions.

LABORsim is a dynamic aging, discrete-event, probabilistic agent-based microsimulation model of labour supply. Setting the focus of LABORsim we gave precedence to the phenomena pointed out in previous section, namely to retirement legislation reforms, the process of seniority accumulation, the changes in the educational choices of young people and the participation behaviours of women. All these factors have been integrated with the best demographic projections available, with an additional focus on migration dynamics. In the balance between the desire to include all relevant dimensions and endogenous feedback of the phenomenon under investigation and the need to keep the model manageable and easy-to-use for policy and scenario evaluations, we pushed towards the latter. Thus there are things that remain excluded from the model, at this stage.

In particular, monetary variables (wages and pensions) are not considered, although future extensions of the model could easily include them. Also, family structure is not considered. However, in estimating an upward trend in participation rates of women, we implicitly take the evolution of family structure into account. Moreover, it should be remembered that, as most microsimulations, LABORsim is not a general equilibrium model. In LABORsim the demand for labour is not considered but for the analysis of unemployment differentials, while the overall unemployment rate is a scenario parameter.

In what follows, we briefly discuss the technical implementation, the data used, and then proceed to describing the overall structure of the model, and the modules it is composed of.

\section{The technical implementation}

From a technical point of view, the main novelty of LABORsim is the choice of an agentbased object-oriented framework. Object-oriented programming allows us to define almost standalone software objects to represent individuals, institutions, etc., each with its own variables and

\footnotetext{
${ }^{5}$ Mitton et al.[(2000] discusses this renewed interest.

${ }^{6}$ For a review of microsimulation literature, see Zaidi and Rake [2002], O'Donoghue [2001] and Anderson [1997, ch.2]

${ }^{7}$ which has nothing to do with the original DYNASIM model cited above
} 
methods. This increases the modularity of the microsimulation, and the transparency of the code. Agent-based models share a common architecture, and often an implementation based on specifically-built object-oriented software platforms. ${ }^{8}$ The use of such platforms has four main advantages: (i) standardization (many technical issues are solved using the software routines); (ii) efficiency (these routines have been designed by professional programmers, rather than by economists that had to learn programming later on in their careers); (iii) brevity (there is less code to write and the code is easier to interpret; hence easier to debug and exchange); (iv) availability of external tools and resources (like graphical interfaces, statistical libraries, etc.).

LABORsim is written in Java, an object-oriented programming language, using JAS (Java Agent-based Simulation Library) ${ }^{9}$, an open source platform for discrete-event agent-based modelling. JAS provides a number of libraries for the management of time, the collection of on-line statistics, on-line graphical widgets and database storage capabilities. Adopting Swarm's original philosophy [Luna and Stefansson, 2000], in addition to providing objects and utilities that make code writing easier and faster, JAS provides templates for the construction of models. The description formalism and the specific semantics used follow the same Swarm protocols, characterized by a clear-cut distinction between the model (a class that provides the environment and executes the simulation) and the observer (a set of routines to look into the model and collect statistics, which are then displayed through a graphical user interface).

Two databases are used to support the simulation, accessed through the standard JDBC-ODBC driver. One contains all technical data, i.e. the initial population, the demographic projections and the estimated parameters, which are not supposed to be modified by the user unless an update is required. The other one (the scenario database) contains the console to manage all scenario parameters. The console is organized into different forms:

- a demography form, to choose which demographic projections are to be used, for natives and for immigrants;

- a participation-to-education form, to set the cohort after which the estimated trend towards higher participation to the schooling system is supposed to halt;

- a probability-of-graduation form, where the estimated probabilities for increasing one's own educational attainment can be varied, for instance in order to mimic the effects of a reform of the schooling system;

- a participation-to-labor market form, to manage the expected trend towards higher participation rates;

- an unemployment differentials form, for changing the estimated coefficients for the unemployment differentials among different groups of the population; this again can be used to mimic the effects of specific policies (e.g. aimed at reducing the negative effect on employability of previous unemployment spells);

- three forms for modifying the parameters governing pension eligibility requirements, one for each scheme (defined benefit, defined contribution and mixed scheme); the default values being those currently considered by legislation;

- three forms for setting the values of the parameters affecting the probability of retirement, given eligibility (one for each scheme).

The output of the simulation consists of online graphics of the most relevant statistics disaggregated by gender and area. Moreover, whenever specified by the user all personal variables of all artificial individuals are recorded in each simulated year, and stored in a panel data structure in the same scenario database. LABORsim also supports a multi-run feature, to allow automatic multiple simulation runs with the same values of the parameters. The results of all simulation runs are stored with a specific run id in the same scenario database.

\footnotetext{
${ }^{8}$ For a review of the literature on agent-based modelling in economics, see Tesfatsion [2001].

${ }^{9} \mathrm{JAS}$ is available from http://jaslibrary.sourceforge.net. See Sonnessa [2004, 2006] for details.
} 
On a standard Mobile Intel Pentium 4 laptop with $1.8 \mathrm{GHz}$ CPU and $360 \mathrm{MB}$ RAM, simulating an initial population of 50,000 individuals up to 2050 takes 3.5 minutes with the online statistics only, and about 1 hour if the panel data creation option is specified (the resulting panel data has more than 2 million records).

\section{The data}

All behavioral parameters have been estimated on waves 1993-2003 of the Rilevazione Trimestrale delle Forze Lavoro (RTFL), the Quarterly Labour Force Survey produced by the Italian Central Statistical Office (Istat).

In particular, the initial population has been derived from the April 2003 RTFL wave, resampling it in order to have a database of about 50,000 individuals all with constant inflating factor. From this, at each run of the simulation a sample of variable size is extracted ${ }^{10}$.

Unfortunately, RTFL data does not include information on seniority, which is relevant for pension eligibility. We recovered this variable with a two step process. First, we imputed the age when individuals started their working career by means of a standard regression imputation, using the European Community Household Panel data (Echp, various waves). The variables common to the two datasets on which age at first job was estimated are age, education, area of residence, sector of activity, marital status and family dimension ${ }^{11}$. The difference between age and age at first job gives a sort of potential seniority.

In a second step, seniority was finally imputed assuming (i) an uninterrupted employment spell for those still at work, and (ii) a continuing spell of participation between the start of the first job and the end of the last job, which we have then discounted by average yearly unemployment rates, conditional on individual characteristics. It should be noted that (i) implies some degree of overestimation, while (ii) leads to some degree of underestimation, since the likelihood of being unemployed is probably higher given past unemployment. The two errors thus (partly) elicit each other. Moreover, this procedure allows us to recover a sufficient amount of variability in individual seniority, including a fair amount of uninterrupted (full seniority) careers.

\section{The model structure}

The simulation is made up of four modules: Demography, Education, Retirement and Employment (see Figure 6) ${ }^{12}$. The Demography module takes care of population ageing, determining the number and characteristics of newborn individuals and of individuals that leave the population, either because they migrate out of Italy or because they die. As regards individuals aged 14 and below and those aged 65 and over no other steps are needed, since they are out of the labour force.

For those who are of working age, we distinguish between three moments in their lifetime: youth (15-30 years), prime age (31-54 years) and old age (55-64). Young individuals decide whether to attend formal education, and - given enrolment - the event whether they get a degree is determined. This is accomplished by the Education module. The next module is concerned only with the elderly, and regards retirement choices (Retirement module). First, eligibility is checked. Eligible individuals then decide whether they want to retire or not.

Young people after 15, prime age individuals and elderly people who are not eligible enter the Employment module (thus, we explicitly model the case of working students). The first decision is whether to participate in the labour market. Conditional on participation, then, their employment status is determined. Eligible people who do not retire, we assume that they are active and employed.

\footnotetext{
${ }^{10}$ Actual simulation runs are generally based on 5,000 to 50,000 artificial individuals.

${ }^{11}$ Pure regression imputation tends to underestimates the variance. Hence, as is standard, we added a noise term to the predicted values in order to avoid this problem.

${ }^{12}$ For more details on the data, model specification and estimation, and scenario parameters, see Leombruni and Richiardi [2005].
} 
Figure 6. The four modules of the simulation.

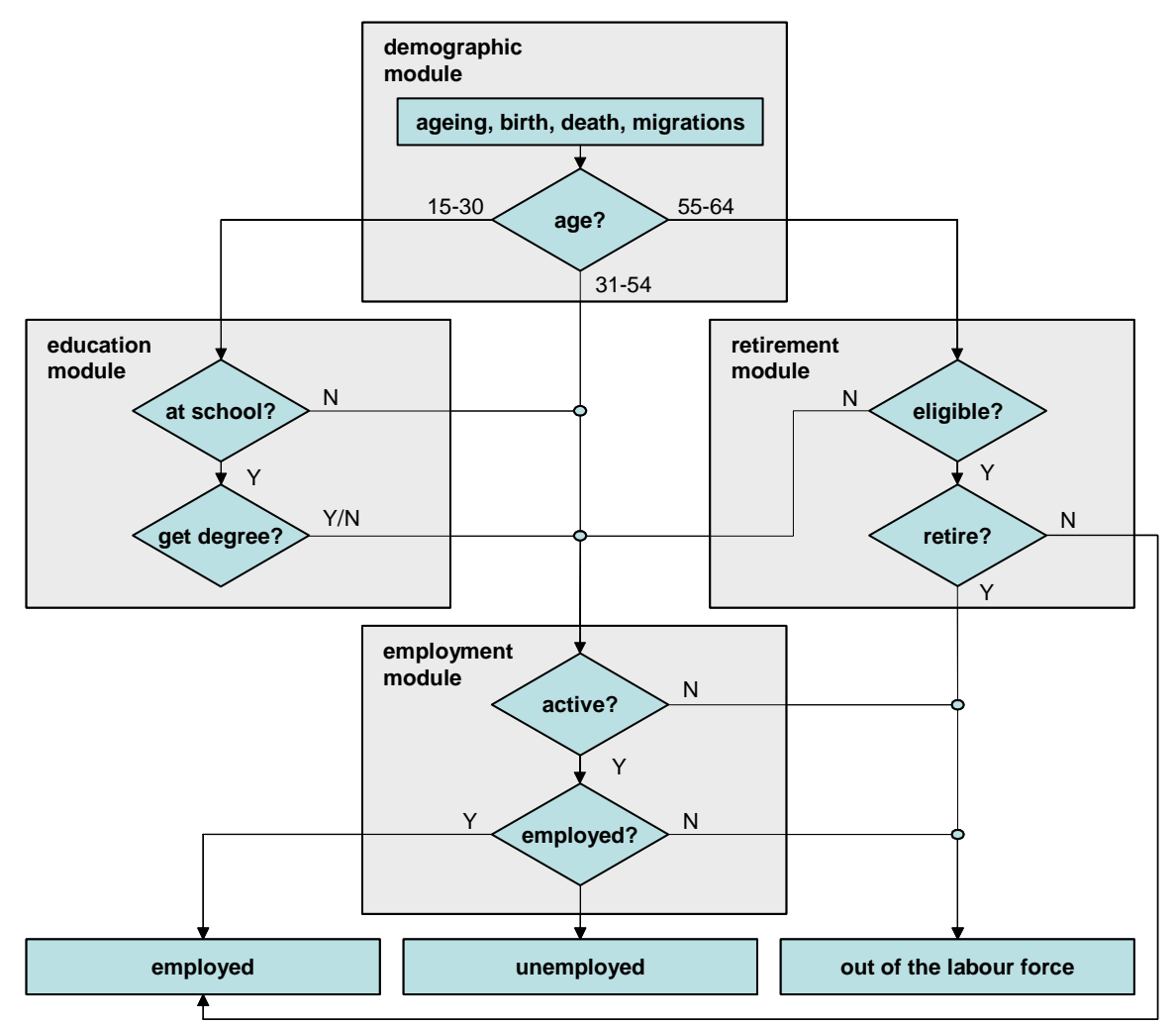

\section{The Demographic module}

The demographic evolution of the simulated population is aligned with Istat projections by sex, age and geographic location. However, official forecasts only consider three scenarios - namely a low, central and high scenario, where all relevant variables (fertility and mortality rates, plus migration) are changed. In order to allow for a richer scenario analysis, we extrapolated from the official projections the separate evolution of natives and immigrants under the three hypotheses. We can thus run our experiments under nine different demographic scenarios. Our spatial analysis focuses on three macro-regions: North, Centre and South of Italy. New cohorts aged 0 identify newborn individuals. The consistency of the simulated population of natives in any sex, age and geographic class is aligned with the projections of the selected scenario by randomly removing or cloning individuals. This is equivalent to the assumption that people who move are ex-ante similar to those who do not move but ex-post similar to the people in the destination area ${ }^{13}$, and allows us to neglect the problem of internal migration. Official statistics also provide projections on the flow of migrants from abroad. We then evolve these foreign immigrants according to the mortality rates used by Istat. Immigrants are supposed to have the same average level of education as the corresponding sex, age and geographical cell, and - given the level of education - to have the same probability to still attend school. We suppose that all immigrants older than 15 who are not students enter in the simulation as employed, and with a seniority of zero. Of course these assumptions reduce the heterogeneity of their career paths. However, immigration in Italy is not as massive a phenomenon as in other Oecd countries: Istat's central demographic projections assume a constant flow of 156,000 new immigrants each year, joining a population of about 57 million in the base year. Hence, the reduction in overall heterogeneity turns out to be negligible.

\footnotetext{
${ }^{13}$ The alternative assumption that migrants keep their pre-migration behaviour is equally arbitrary. Note that there is very little data concerning the behaviour of individuals before and after migration.
} 


\section{The Education module}

This module is formed by two sub-modules, one for determining the status of student and the other for determining whether the individual gets his/her degree. We consider three levels of education: basic, diploma and university degree. The first level is compulsory, and we model it as driven only by age. As Figure 7 shows, we detect an increasing trend towards higher participation rates, both for high school and for university. We model this trend linearly, and estimate the probability of being a student conditional on sex, age, geographical location, lagged status as student and cohort (Table 1 and 2). The reference group is composed of non-student males living in the South.

Figure 7. Cohort-effects in schooling participation rates, high school (left panel) and university (right panel). Coefficients of year-of-birth dummies in a logit regression reported.
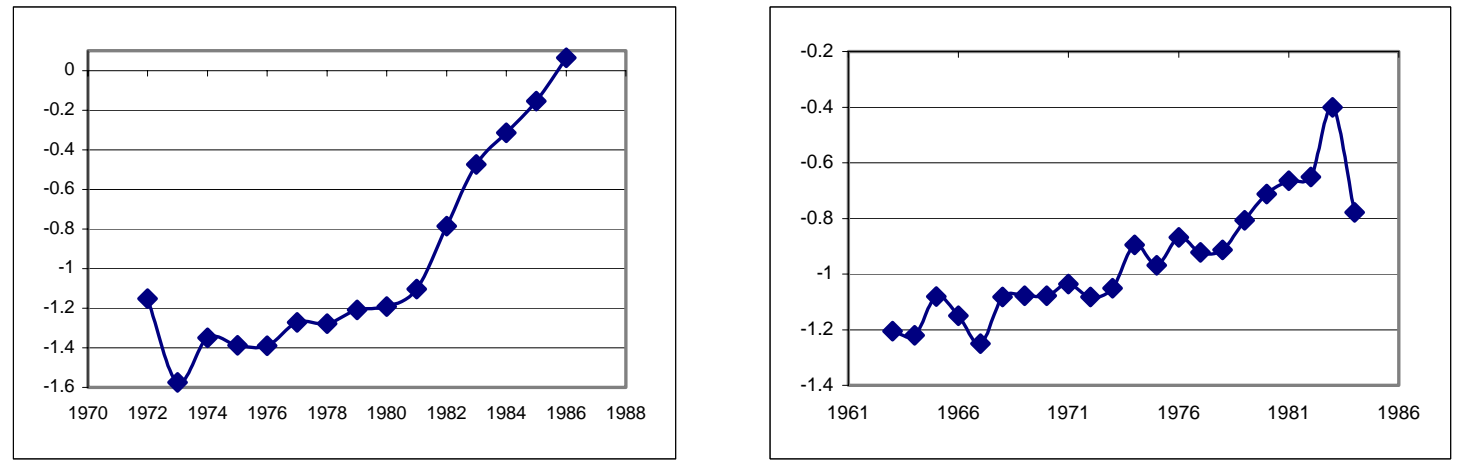

Source: Our calculations using Istat data, RTFL, 1993-2003

Table 1: Logit estimates for high school participation. Data: Istat, Rtfl, 1993-2003

$\begin{array}{lcrrr}\text { Number of obs. } & \begin{array}{c}106,022 \\ \text { Estimate }\end{array} & \text { Error } & \text { Chi-Square } & \text { Pr }>\text { ChiSq } \\ \text { Parameter } & 0.2950 & 0.0297 & 98.9079 & <.0001 \\ \text { woman } & -0.1575 & 0.0323 & 23.7897 & <.0001 \\ \text { north } & 0.2466 & 0.0428 & 33.1466 & <.0001 \\ \text { center } & 5.7608 & 0.0330 & 30411.2442 & <.0001 \\ \text { lagged student } & 3.1394 & 0.2329 & 181.6358 & <.0001 \\ \text { age } & -0.0919 & 0.00637 & 207.9202 & <.0001 \\ \text { age squared } & 0.1137 & 0.00480 & 562.3682 & <.0001 \\ \text { Cohort } & -254.6 & 9.8287 & 671.1519 & <.0001 \\ \text {-const } & & & & \end{array}$

Table 2: Logit estimates for university participation. Data: Istat, Rtfl, 1993-2003

\begin{tabular}{lrr} 
Number of obs. & \multicolumn{1}{c}{167,564} & \\
Parameter & Estimate & Error \\
woman & 0.2152 & 0.0198 \\
north & -0.4721 & 0.0223 \\
center & -0.1580 & 0.0272 \\
lagged student & 5.6032 & 0.0252 \\
age & 1.8367 & 0.0475 \\
age squared & -0.0373 & 0.000995 \\
cohort & 0.0336 & 0.00317 \\
_const & -92.0507 & 6.3470
\end{tabular}
Chi-Square
118.4854
448.2335
33.7918
49629.8288
1495.9943
1409.3989
112.5205
210.3386
$\operatorname{Pr}>\mathrm{ChiSq}$
$<.0001$
$<.0001$
$<.0001$
$<.0001$
$<.0001$
$<.0001$
$<.0001$
$<.0001$

In the scenarios consolle we allow the user to choose a cohort after which the linear trend towards increasing participation comes to a stop.

The probability of graduating is also estimated using Rtfl data, from 1998-2003, based only on age. Figure 8 shows the estimated probability and the approximation implemented in Labor Sim, which maintains the overall probability of getting a degree, within the age bracket considered, equal to the empirical one. We assume that everybody leaves high school before 22 , and that no one 
attends university after 30, an assumption not too far from what we observe in the data (only $1.2 \%$ of people aged 22 are still enrolled at high school, while only $2.9 \%$ of people aged 31 are still attending university; both figures decrease with age).

Figure 8. Probability of graduating, high school (left panel) and university (right panel).
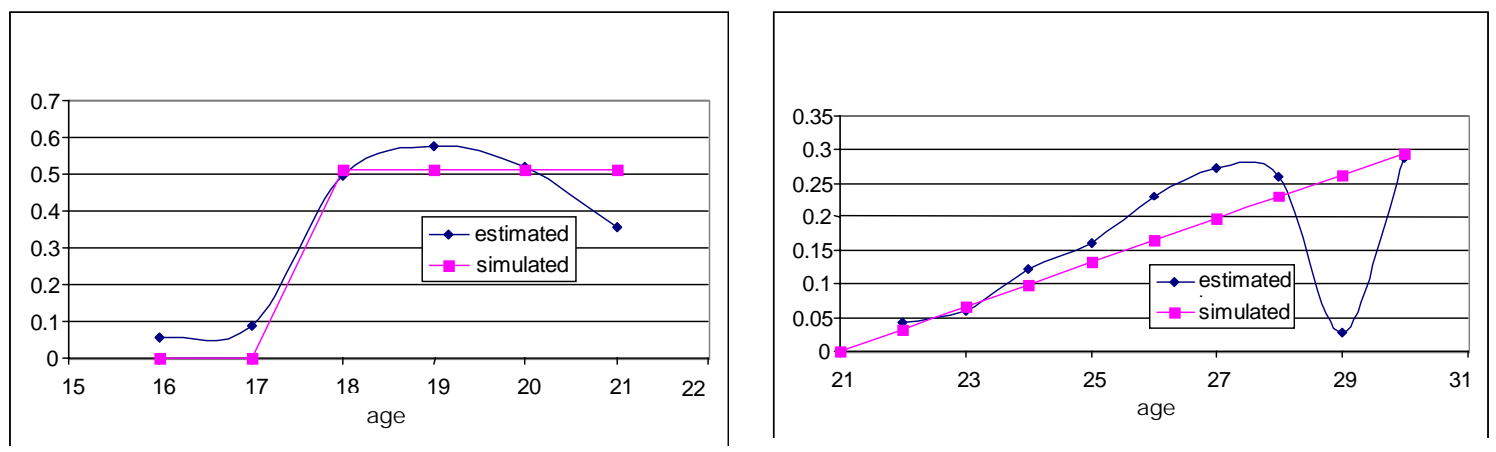

Source: Our calculations using Istat data, RTFL, 1993-2003

Thus, educational paths are completely modeled. For any individual below 30 we know whether s/he is still in the educational system, and what degree(s) s/he has. We may have students who work, students that drop out before completing the degree, students that had dropped out and returned to school.

\section{The Retirement module}

This module is based on the distinction between eligibility and retirement choice. Given Italian legislation, time, age and simulated seniority, eligibility is deterministically determined. In short, the legislation identifies three different schemes, according to seniority in 1995: the old definedbenefit, pay-as-you-go scheme for workers who had more than 18 years of seniority in 1995, the new defined-contributions, funded scheme for workers who started working after 1995, and a mixed scheme for workers who had less than 18 years of seniority in 1995 . The detailed eligibility criteria up to the Maroni reform inAugust 2004 for these three schemes has been implemented in the model. ${ }^{14}$

The choice of postponing retirement can be affected by a number of issues. In the past, with an extremely generous welfare scheme for pension holders, many workers decided to retire as early as possible. This has been particularly true during the reform period, as workers were afraid to postpone retirement fearing that the rules could change against them. With the purpose of improving the balance of the system some proposals have been discussed recently, aimed at creating incentives for workers to postpone retirement. In order to allow the creation of flexible scenarios, and given that there is poor data on which to estimate the retirement propensity, we have modelled the retirement choice in an entirely parametric way: the user must specify the probability of retiring as early as possible (i.e. as soon as the individual becomes eligible) and the probability of postponing retirement until the age of 65 . These two parameters are sex, education and schemespecific. For each parameter, two values must be imputed: one for the base year, and one for the final year of the simulation. In each simulated year a linear interpolation of these two extremes is then used. The residual probability of retiring is distributed in the interval between age of eligibility and 65 according to a simple algorithm specifying that, given a cohort of individuals becoming eligible at the same age, the flow into retirement must remain constant. ${ }^{15} 16$

\footnotetext{
${ }^{14}$ For a detailed account of the Maroni reform, together with its evaluation within the LABORsim framework, see Leombruni and Richiardi [2006]

${ }^{15}$ A more detailed description of the algorithm can be found in Leombruni and Richiardi [2005].
} 


\section{The Employment module}

The employment status of individuals is simulated in two steps: First, their participation in the labour market is decided; conditional on participating, then, the employment/unemployment status is simulated.

As already mentioned, labour market participation choices seem to entail a relevant cohorteffect, especially for women. We modelled participation as a function of lagged participation, a polynomial of age, year of birth, the status of student and the educational level, by conditioning on not being retired. The choice of a linear specification of the cohort-effect was made after a preliminary analysis of the coefficients of specific year-of-birth dummies ${ }^{17}$.

Figure 9. Cohort-effect in labour market participation rates, males (left panel) and females (right panel). Coefficients of year-of-birth dummies in a logit regression reported.
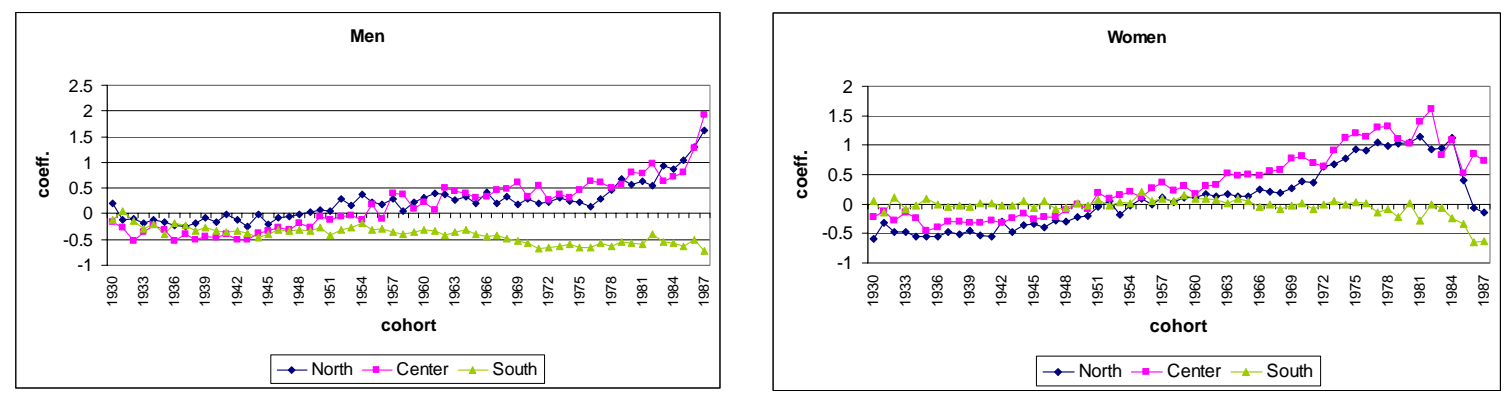

Source: Our calculations based on Istat, RTFL, 1993-2003

Not factoring in life-cycle factors such as family formation processes could weaken the ability of the model to capture sufficient heterogeneity in employment paths. However conditioning participation rates on lagged activity status, in addition to other individual characteristics, brings enough heterogeneity for the purpose of the model (forecasting aggregate participation rates, rather than obtaining realistic individual career paths).

We estimated this model separately by sex and geographical area, and found significant cohort-effects in most subgroups (see Figure 9). The only exception is for the South of Italy, where the cohort-effect is less significant, and reversed. For the sake of brevity we chose not to report all six sets of regression results. However, in order to give the reader an idea of the estimated dynamics we report the results of two additional logit regressions for the participation probability, for males and females, pooling together the three macro-areas (Table 3 and Table 4 below). The reference group is composed of low-educated, previously inactive non-students.

\footnotetext{
${ }^{16}$ Mazzaferro and Marciano [2005] adopt a similar approach and model retirement decisions parametrically. They suppose that individuals retire immediately if they become eligible due to age requirements, while they have a retirement propensity of .5 in each year if they become eligible due to the seniority requirement. In Vagliasindi et al. [2004] individuals choose the timing of retirement by looking at the differential benefit of postponing retirement to the following year. The empirical evidence on retirement choices has been investigated by Spataro [2005], Brugiavini and Peracchi [2004, 2003], Marano and Sestito [2004], Colombino et al. [2002], Colombino [2000] and Miniaci [1998].

${ }^{17}$ Note that the interpretation of the dummy coefficients in Figure 8 as full cohort-effect is not straightforward, since we included the lagged participation status (which is correlated with the cohort-effect) as an explanatory variable.
} 
Table 3: Logit estimates for male labour market participation. Data: Istat, Rtfl, 1993-2003

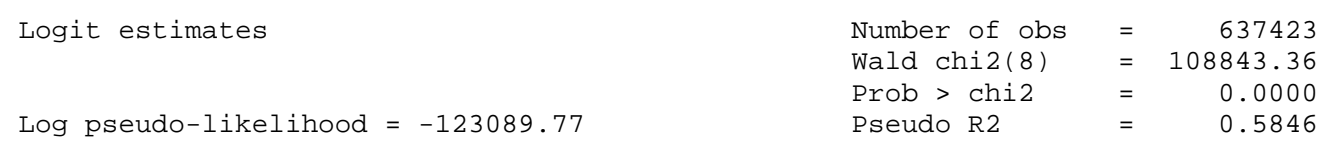

\begin{tabular}{r|rrrrrr} 
part. & Coef. & $\begin{array}{c}\text { Robust } \\
\text { Std. Err. }\end{array}$ & $\mathrm{z}$ & $\mathrm{P}>|\mathrm{z}|$ & [95\% Conf. Interval] \\
\hline lagged part. & 2.968351 & .0138102 & 214.94 & 0.000 & 2.941284 & 2.995419 \\
age & .1215354 & .0132734 & 9.16 & 0.000 & .09552 & .1475507 \\
age squared & .0006595 & .0003399 & 1.94 & 0.052 & $-6.58 \mathrm{e}-06$ & .0013257 \\
age cubed & -.0000314 & $2.76 \mathrm{e}-06$ & -11.39 & 0.000 & -.0000368 & -.000026 \\
student & -3.165786 & .0284844 & -111.14 & 0.000 & -3.221615 & -3.109958 \\
diploma & .5887948 & .0147846 & 39.82 & 0.000 & .5598176 & .617772 \\
univ. degree & .9996766 & .0280698 & 35.61 & 0.000 & .9446608 & 1.054692 \\
cohort & .0040348 & .0018856 & 2.14 & 0.032 & .0003392 & .0077305 \\
const & -11.34523 & 3.765515 & -3.01 & 0.003 & -18.7255 & -3.96495 \\
\hline
\end{tabular}

Table 4: Logit estimates for female labour market participation. Data: Istat, Rtfl, 1993-2003

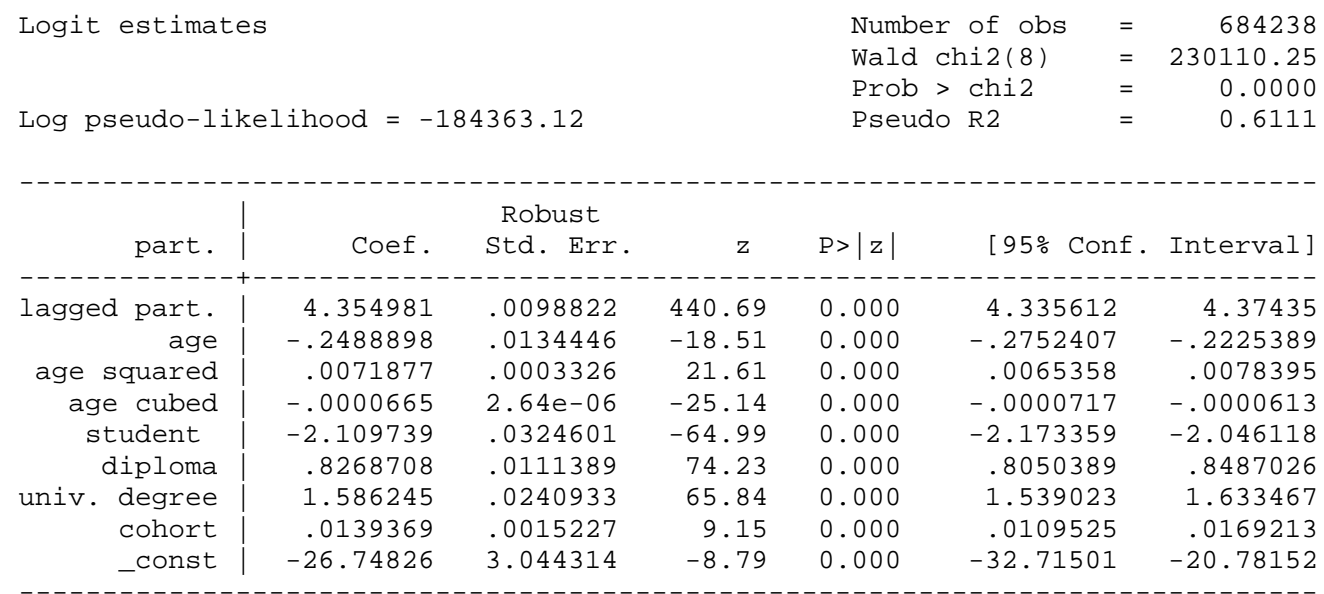

In the scenarios consolle we let the user specify the cohort after which the trend stops. However, since it is hard to believe that the weak but negative cohort-effect in the South will continue in the future, we removed the year-of-birth variable in the related regressions (both for males and females). We also added two additional convergence effects, one by gender and the other by area, that by default are set to zero. By setting them to a positive value one can choose to let participation rates in the South of Italy become closer to participation rates in the North, participation rates for women become closer to participation rates for men, or both. The user has to specify the fraction of the gap that has to be filled in each year of the simulation. This option becomes valuable for scenario analysis and policy evaluation, since it can be used to mimic the effects of specific policies aimed at increasing participation rates for subgroups of the population where they are particularly low.

Finally, we come to the employment status. As already mentioned, the microsimulation model does not model the demand side of the economy. Consequently, the employment module simply aims at reproducing the observed heterogeneity in unemployment rates across subgroups. The average unemployment rate in each simulated year is an exogenous parameter to be set by the user. To estimate the unemployment differentials we modelled the probability of becoming unemployed as a function of lagged unemployment, sex, age class (below 20, 20-50, over 50), educational level, geographical area and the average overall unemployment rate with a logit regression. We thus replaced the usual value of 1 for the constant with the average overall unemployment rate. The reference group is composed of prime age employed men living in the North with high school diplomas. 
Table 5: Logit estimates for unemployment. Data: Istat, Rtfl, 1993-2003

\begin{tabular}{lrrrr} 
Number of obs. & \multicolumn{2}{c}{860,172} & & \\
Parameter & Estimate & Error & Chi-Square & Pr $>$ ChiSq \\
unempl. rate & -36.4554 & 0.1095 & 110834.681 & $<.0001$ \\
female & 0.7660 & 0.00872 & 7718.4177 & $<.0001$ \\
low education & 0.1398 & 0.00912 & 235.2739 & $<.0001$ \\
univ. degree & -0.5715 & 0.0176 & 1053.8429 & $<.0001$ \\
center & 0.2625 & 0.0125 & 444.2999 & $<.0001$ \\
south & 1.0572 & 0.00962 & 12083.8515 & $<.0001$ \\
lagged unempl. & 3.0731 & 0.00924 & 110652.437 & $<.0001$ \\
young & 0.9247 & 0.00904 & 10466.5191 & $<.0001$ \\
old & -0.5818 & 0.0159 & 1331.7270 & $<.0001$
\end{tabular}

\section{Results}

\section{The standard scenario}

Our standard scenario ${ }^{18}$ replicates exactly Istat's central demographic projections up to 2050, i.e. we choose the central forecast both for natives and immigrants. We conservatively assume that the linear trend towards increasing participation to education ends for individuals entering high school and university in the base year, i.e. respectively born after 1990 and 1985. Analogously, we assume that the trend towards increasing labour market participation stops for individuals born after 1980 . The additional convergence effects by gender and area are set to zero. The average unemployment rate is set to a constant value of $8 \%$ of the work force for all simulated years. We assume that the probability of postponing retirement, given eligibility:

(i) depends on the pension scheme, the defined-benefit scheme being not actuarially fair and thus providing stronger incentives for early retirement ${ }^{19}$;

(ii) depends on education, higher education being generally associated with higher utility from work;

(iii) does not depend on gender, given that eligibility criteria for men are already stricter than those for women.

Table 6. Standard scenario parameters.

\begin{tabular}{llll}
\hline \multicolumn{3}{l}{ Education } & \\
\hline & Basic & High School & University \\
Defined-benefits \& Mixed & & & \\
\% early retirement & 0.7 & 0.6 & 0.5 \\
\% late retirement & 0 & 0.1 & 0.2 \\
Defined-contributions & & & \\
\% early retirement & .4 & .3 & .2 \\
\% late retirement & .2 & .3 & .4 \\
\hline
\end{tabular}

The Maroni reform also allows women in the defined benefit and mixed scheme to retire earlier by switching to the defined-contribution scheme, that is by accepting a lower pension. We assume that only a few women will actually choose this opportunity, and that the majority of female workers $(60 \%)$ will wait for the other eligibility criteria to be met.

\footnotetext{
${ }^{18}$ For a detailed account of the results of the standard scenario, see Leombruni and Richiardi [2005]

${ }^{19}$ the Maroni reform (August 2004) tried to counterbalance this bias by introducing monetary incentives in order to induce workers to postpone retirement.
} 
Table 6 summarizes. All these values are assumed to remain constant for all simulation periods.

\section{Education}

The graph below shows the evolution of the distribution of educational levels in the standard scenario.

Figure 10. Evolution of the educational attainment distribution, people aged 55-64.

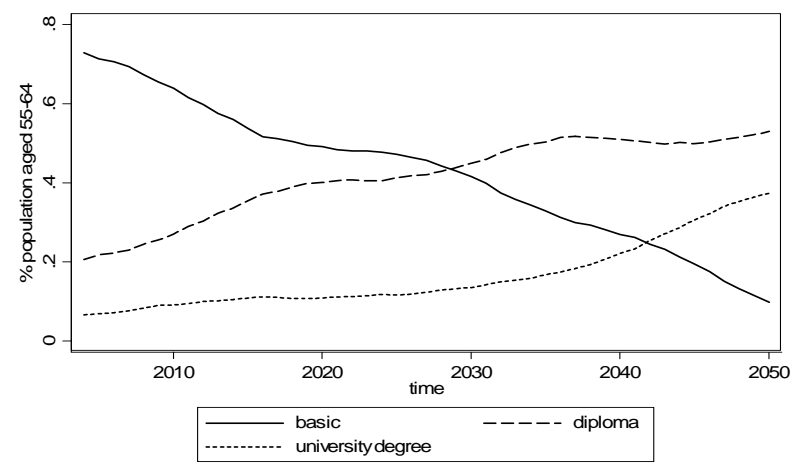

Source: LABORsim standard scenario.

Even if the trend towards higher participation in the educational system has been stopped for the future, the simple demographic effects of younger cohorts replacing older ones with lower education are important. The share of people having attainted a university degree is expected to rise to over $20 \%$ of the population by 2040 .

\section{Participation}

Higher educated people tend to participate more in the labour market. Thus, the effects of the changes in the composition of the working age population described above, together with the effects of tightening requirements for retirement and the replacement of older cohorts with younger, more active, cohorts, imply higher participation rates. This holds even without extending the estimated trend towards higher participation rates beyond the level reached by younger cohorts in the initial population.

Figure 11. Projected participation rates as a share of population in working age (left panel) and of population aged 55-64 (right panel).
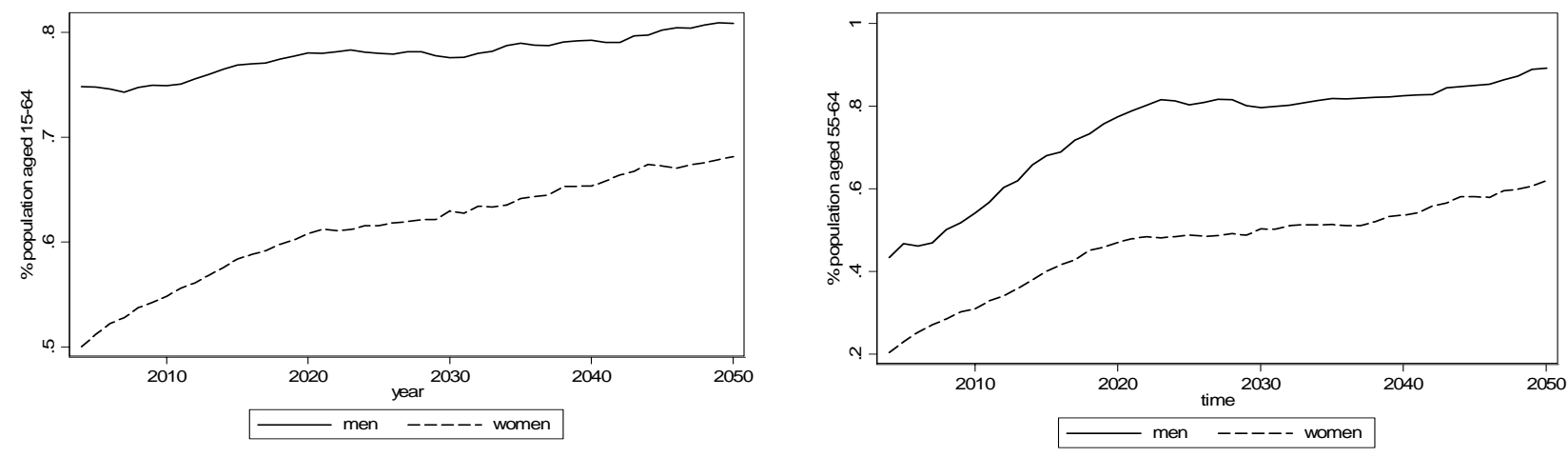

Source: LABORsim standard scenario.

Note that these projections, although based on conservative assumptions, are more optimistic than those generally available in the literature. Figure 12 shows our forecast for the evolution of the 
labour force: it is expected to increase steadily for the next two decades, and to start decreasing only after 2020, when the baby boom generations become eligible to retire. As a comparison, the "constant" scenario in Oecd [2004] (which assumes constant participation rates by gender and fiveyear age groups) forecasts a steady decrease in the labour force to below 17 million in 2050, while the "average" scenario (which assumes that participation rates will reach the Oecd average by 2030) forecasts a drop in the labour force to below 19 million. Our forecasts for 2050 remain above 21 million.

Figure 12. Evolution of the labour force, thousands of individuals

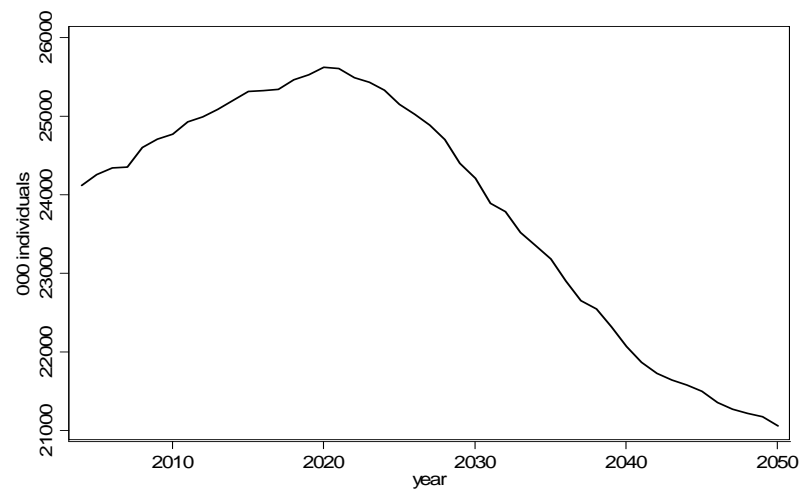

Source: LABORsim standard scenario.

Figure 12 shows the evolution of the age profile of participation rates. The profile for men shifts towards older ages from the base year to the final year of the simulation. The profile for women, in addition to the shift towards older ages, shows also a significant shift upwards.

Figure 13. Participation rates, age profile for the base and final year.

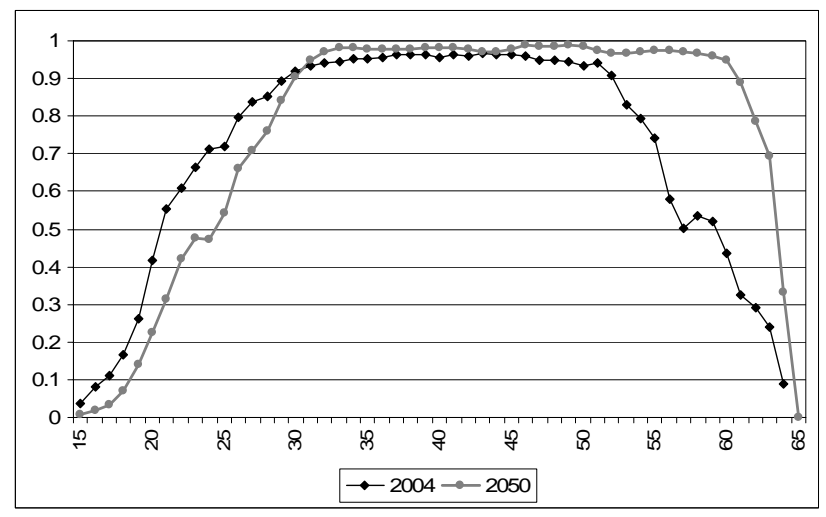

(a) men

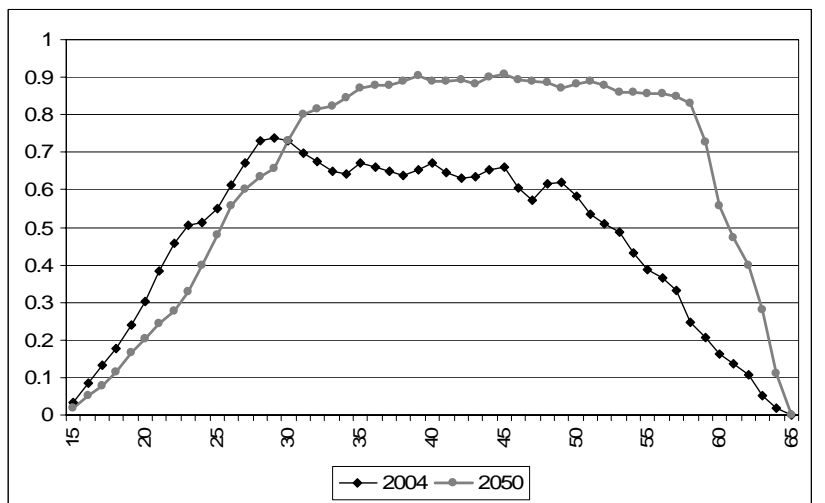

(b) women

Source: LABORsim standard scenario.

The implications on the economic dependency rate are shown in Figure 14. Instead of the rise predicted by most projections (see section 2 above), we actually forecast a decrease in the dependency rate. An increase is expected to take place only after 2020, as the baby boomers gradually retire from the labour market. However, we forecast that the economic dependency rate will stabilise in the final years of the simulation around a value only $10 \%$ higher than in the base year. 
Figure 14. Evolution of the demographic and economic dependency rates, population over 20 years of age.

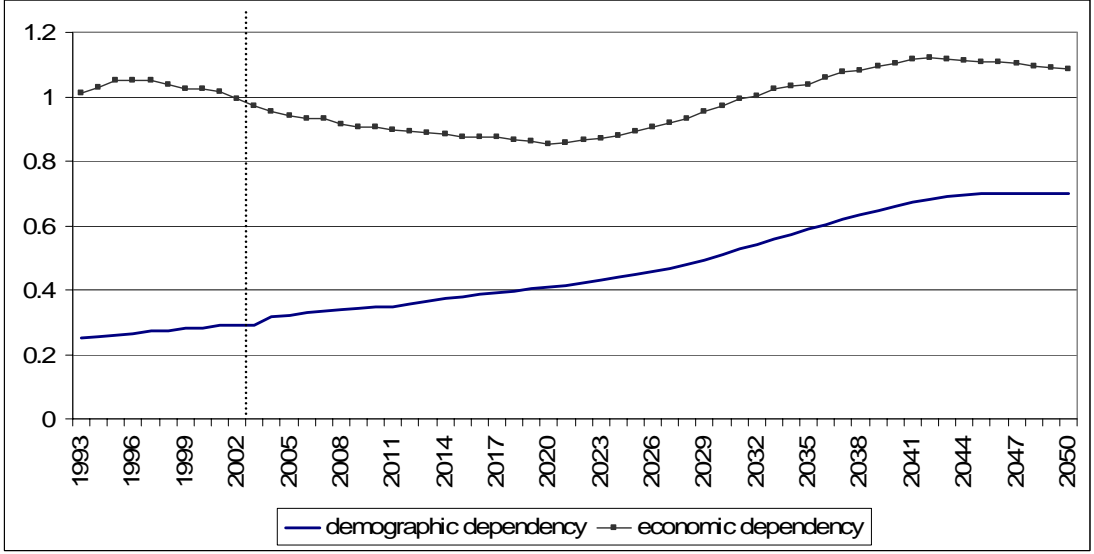

Demographic dependency rate: 65 and over / 20 and over

Economic dependency rate: inactive, 20 and over / active, 20-64

Source: Istat, RTFL 1993-2003 and LABORsim standard scenario.

\section{Employment and the EU targets}

The European Council has set (Lisbon, March 2000) the long run goal of full employment for the European economy, agreeing upon a 2010 target of a $70 \%$ overall employment rate for the population aged 15-64 (60\% for the female employment rate). The European Council later set (Stockholm, March 2001) short term target for 2005, and a new 2010 target of a 50\% employment rate for the elderly (aged 55-64).

Although we forecast higher participation rates, we predict that Italy will not be able to reach the overall and female targets for many decades to come (Figure 15, left panel). The sharp increase in the participation rates for the elderly (aged 55-64) however, mainly driven by the recent changes in the retirement eligibility criteria, will make it possible to meet the Stockholm target of a 50\% employment rate in this age group by 2015 , i.e. with only a 5 year delay (Figure 15 , right panel).

Figure 15. Projected employment rates as a share of the population of working age (left panel) and of population aged 55-64 (right panel).
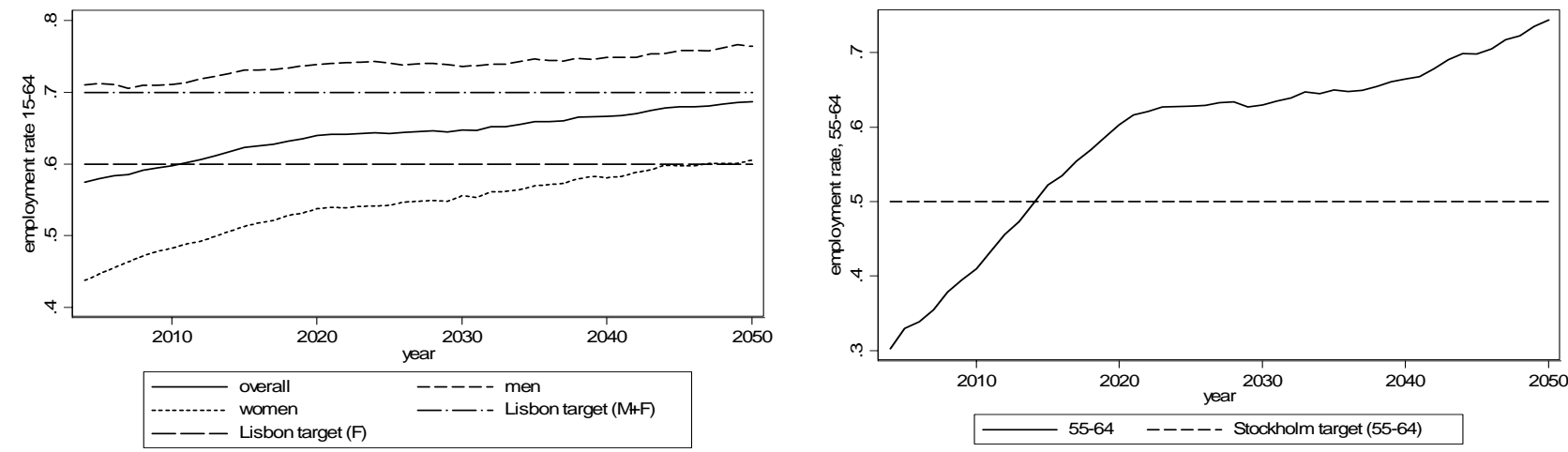

Source: LABORsim standard scenario.

\section{Retirement}

Finally, the effects of the reforms of the pension system undertaken in the period 1992-2004 are clearly visible in the left panel of Figure 16, which depicts the share of eligible and retired workers in the age bracket 55-64. The differing trend for women can be explained (a) with the differences introduced by the Maroni reform in the eligibility requirements for men and for women (more 
generous for the latter), and (b) with the increasing female participation rate documented above, which increases the number of women who can claim a pension. Note that as the share of workers belonging to the defined contribution scheme increases, the gap between women who can retire and women who actually choose to retire increases. This is due to the differing values of the parameters governing retirement choice for the two schemes (see table 6 above), which account for the waning of the bias towards early retirements implicit in the legislation. The same parameters are valid for both genders. However, the Maroni reform has decreased the freedom men have in choosing when to retire, hence the figure for retired male workers follows more closely that of eligible male workers.

Figure 16. Share of eligible and retired workers, aged 55-64, by gender.

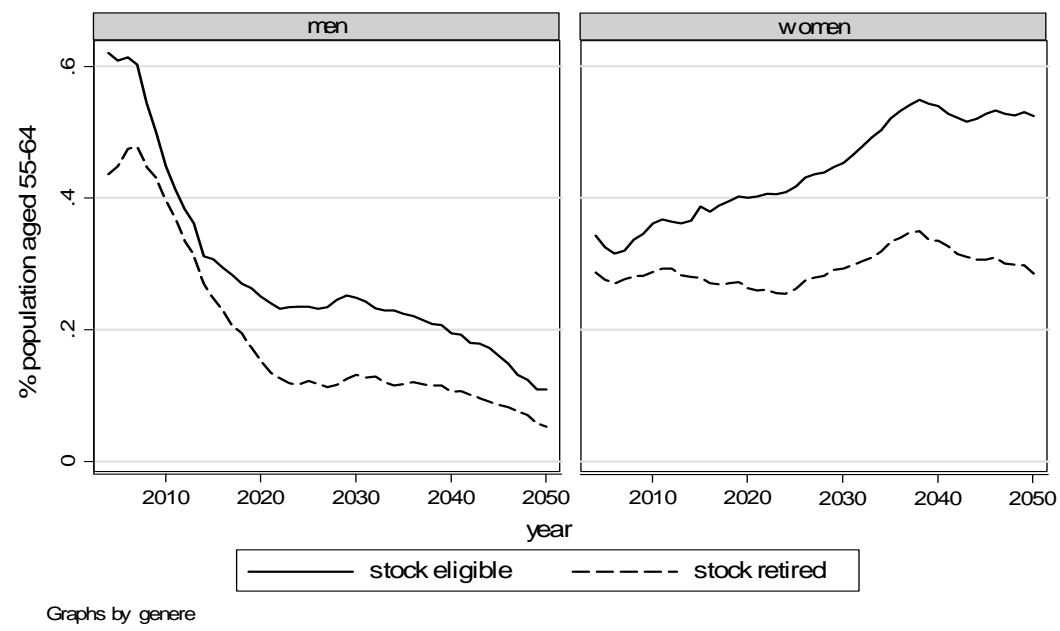

Source: LABORsim standard scenario.

\section{Conclusions and further developments}

In this paper we have presented LABORsim, a dynamic ageing, discrete-event, probabilistic agent-based microsimulation model of labour supply, and an application to Italy. The Italian case is interesting because of the combination of rapid population ageing and low participation rates of the elderly. Due to these two causes, it is generally argued that Italy will experience a sharp decline in the labour force in the forthcoming decades, with a consequent increase in the economic dependency rate (the ratio of inactive to active people). In contrast, we show that changes in retirement legislation, educational choices, working careers, the participation behaviours of women will countervail the demographic ageing of the population, allowing Italy to meet the Lisbon and Stockholm targets earlier than previously expected.

The welfare implications of these projections have not been addressed. Old people will work more in the future, and as a consequence they will impose a lower burden on younger generations. However, these people could possibly be worse-off with respect to old people now, remaining at work at older ages possibly reflecting both a choice and a necessity. That is, many people will choose to study more, thus delaying their entrance into the labour market. On the other side, due to a less favourable pension scheme people will need to work more in order to sustain their income. Moreover, if the trends toward a reduction in family size and an increase in job precariousness detectable now in the data continue, intergenerational solidarity could be affected (in either way: from young to old people and vice-versa), with significant welfare implications.

In order to investigate these issues it is necessary to explicitly model income and family networks. We thus plan to include new modules in LABORsim, to deal with wages, pensions and family evolution. 
The modular structure of LABORsim, as the separation between the code and the input data, allow for an easy application of the model to different national contexts. Hence, we also plan to use LABORsim for cross-country comparisons, and for the evaluation of policy proposals both at a national and EU level. 


\section{References}

Anderson J.M. (1997), Models for Retirement Policy Analysis, Report to the Society of Actuaries, Capital Research Associates

Ando A., Brandolini A., Bruno G., Cannari L., Cipollone P., D’Alessio G., Faiella I., Forni L., Marino M.R., Nicoletti Altimari S. (2000), The Bank of Italy's DYNAMITE: Recent Developments, mimeo, Banca d'Italia, Roma

Bonnet C. and Mahieu R. (2000), Public pensions in a dynamic microanalytic framework: the case of France, in Mittono L., Sutherland H. and Weeks M. (eds.), Microsimulation Modelling for Policy Analysis. Challenges and Innovations, Cambridge University Press, Cambridge, UK.

Brugiavini A. and Peracchi F. (2004), Micro-Modelling of Retirement Behavior in Italy, in Gruber J., Wise D.A. (eds), Social Security Programs and Retirement Around the World. Micro-Estimation, National Bureau of Economic Research Conference Report

Brugiavini A. and Peracchi F. (2003), Social security wealth and retirement decisions in Italy, Labour, 17 (special issue), 79-114

Colombino U, Hernæs E., Jia Z. and Strøm S. (2002), Retirement in Italy and Norway, CHILD Working Paper No.22/2002

Colombino U. (2000), Un modello per la valutazione degli effetti degli incentivi individuali sulle decisioni di pensionamento, Ministero del Tesoro, Commissione Tecnica per la Spesa Pubblica

Curry C. (1996), PENSIM: A Dynamic Simulation Model of Pensioners' Incomes, Department of Social Security, London

European Commission Social Protection Committee (2003), Report on national strategies for future pension systems (ITALY 2002), in National strategy reports (2002): adequate and sustainable pension systems, http://europa.eu.int/comm/employment_social/social_protection/index_en.htm

Favreault M. M. and Caldwell S. B. (1999), Assessing Distributional Impacts of Social Security by Cohort, Gender, Family Status, Lifetime Earnings and Race Using Dynamic Microsimulation, The Urban Institute, Department of Sociology, Cornell University, USA.

Fredriksen D. (1998), Projections of Population, Education, Labour Supply and Public Pension Benefits: Analysis with the Dynamic Microsimulation Model MOSART,. Social and Economic Studies, Statistics Norway, Oslo.

King A., Baekgaard H. and Robinson M. (1999), DYNAMOD-2: An Overview, Technical paper no. 19, National Centre for Social and Economic Modelling (NATSEM), University of Canberra, Australia.

Leombruni R. and Richiardi M. (2005), Strumenti di previsione dei tassi di occupazione per età, con particolare riferimento ai lavoratori anziani, Ministero del Lavoro, Italy

Leombruni R. and Richiardi M. (2006, forthcoming), An Evaluation of the 2004 Pension Reform in Italy with LABORsim, LABORatorio R. Revelli WP series

Luna F. and Stefansson B. eds. (2000), Economic Simulations in Swarm: Agent-Based Modelling and Object Oriented Programming, Kluwer Academic, Dordrecht and London 
Marano, A. and P. Sestito (2004), Older workers and pensioners: the challenge of ageing on the Italian public pension system and labour market, in E. Fornero and P. Sestito (eds.) Pension Systems: Beyond Mandatory Retirement, Edward Elgar.

Mazzaferro C. and Marciano M. (2005), Un modello di microsimulazione a popolazione dinamica per la stima degli effetti distributivi della riforma pensionistica, CAPP Working Paper

Miniaci, R. (1998), Microeconometric analysis of the retirement decision in Italy, OECD Economic Department Working Paper No. 205.

Mitton L., Sutherland H. and Weeks M. (2000), Microsimulation Modelling for Policy Analysis. Challenges and Innovations, Cambridge University Press, Cambridge, UK.

O’Donoghue C. (2001), Dynamic Microsimulation: A Methodological Survey, Brazilian Electronic Journal of Economics, Vol. 4, No. 2

OECD (2004), Ageing and Employment Policies / Vieillissement et politiques de l'emploi - Italy, Paris.

Orcutt G. (1957), A new type of socio-economic system, Review of Economics and Statistics, Vol. 58, pp 773-797

Ragioneria Generale dello Stato (2004), Le tendenze di medio-lungo periodo del sistema pensionistico e sanitario, rapporto $\mathrm{n}^{\circ} 6$, dicembre

Scott, A and Zaidi, A (forthcoming) Education and Labour Market Predictors in the SAGE Dynamic Microsimulation Model, technical note 9, ESRC SAGE Research Group, London School of Economics, London.

SAGE (2001-2004), Technical Notes, http://www.lse.ac.uk/collections/SAGE/technicalNotes.htm

Spataro L. (2005), Social Security and Retirement Decisions in Italy: an empirical insight, Research in Economics 59 (3), 223-56

Sonnessa M. (2004), The JAS (java agent-based simulation) library, in Leombruni R. and Richiardi M. (eds.), Industry and Labor Dynamics: The Agent-based Computational Economics Approach. Proceeding of the Wild@Ace 2003 conference, World Scientific Press, Singapore

Sonnessa M. (2006), Jas, in Terna P., Boero R., Morini M. and Sonnessa M. (eds)., Simulazione, modelli ad agenti e scienze sociali, Il Mulino, Milano

Tesfatsion, L. (2001), Agent-based computational economics: A brief guide to the literature, in Jonathan Michie (ed.) Reader's Guide to the Social Sciences, vol. 1, Fitzroy-Dearborn, London, 2001.

Vagliasindi P., Romanelli M. and Bianchi C. (2004), Early Retirement From the Labour Market: Policy Experiments in the Italian Case, in Leombruni R. and Richiardi M. (eds.), Industry and Labor Dynamics: The Agent-based Computational Economics Approach. Proceeding of the Wild@Ace 2003 conference, World Scientific Press, Singapore

Wertheimer R., Zedlewski S. R., Anderson J. and Moore K. (1986), DYNASIM in comparison with other microsimulation models. in Orcutt G. H., Merz J., and Quinke H. (eds.), Microanalytic Simulation Models to Support Social and Financial Policy, Elsevier Science Publishers, Amsterdam, pp. 187-206 
Zaidi A. and Rake K. (2002), Dynamic microsimulation models: a review and some lessons for SAGE, Sage discussion paper n. 2. 